\title{
Vulnerabilidade da Criança no Varejo: Um Estudo Sob a Perspectiva da Pesquisa Transformativa do Consumidor
}

\section{Child Vulnerability in Retail: A Study Under the Perspective of Transformative Consumer Research}

\author{
Ohana Trajano Barbosa ${ }^{1}$, Andres Rodriguez Veloso ${ }^{1}$ \\ ${ }^{1}$ Faculdade de Economia, Administração e Contabilidade, FEA, Universidade de São Paulo, USP, Brasil \\ Correspondência: Ohana Trajano Barbosa. Endereço: Av. Prof. Luciano Gualberto, 908, Butantã, São Paulo, SP \\ CEP 05508010. Tel.: 5511 3091-5960.E-mail: ohanatrajano@ hotmail.com
}

Recebido: 30 de junho de 2017 Aceito: 28 de setembro de 2017 Publicado: 01 de novembro de 2017

DOI: http://dx.doi.org/10.21714/1679-18272017v15n1.p1-10

\begin{abstract}
Resumo
Dentre os temas estudados sob a 'lente' da Pesquisa Transformativa do Consumidor (TCR), tem-se a vulnerabilidade, que representa um estado de impotência diante um desequilíbrio nas interações de mercado ou do consumo de produtos e mensagens de marketing. Neste estudo, o foco incide no consumidor infantil. No que diz respeito a vulnerabilidade deste mercado, este tema não tem sido amplamente estudado e o campo carece de pesquisas. Nesse sentido, o presente artigo tem por objetivo identificar as vulnerabilidades do consumidor infantil vivenciadas no varejo. Para tanto, realizou-se uma pesquisa exploratória de natureza qualitativa, na qual a coleta de dados se deu por meio de redações realizadas junto a crianças com idade entre oito e nove anos, estudantes de uma escola do interior do estado de São Paulo. A análise dos dados de se deu por meio da categorização das informações e análise de conteúdo. A partir dos dados, foi possível perceber que a vulnerabilidade da criança no varejo está mais associada com a presença de fatores externos, como por exemplo, ausência dos produtos desejados na loja, dificuldade de encontrá-los, possibilidade de não identificar o produto devido as embalagens com desenhos, entre outros, do que com as características individuais das crianças.
\end{abstract}

Palavras-chave: Pesquisa Transformativa do Consumidor. Vulnerabilidade. Consumidor infantil.

\begin{abstract}
Among the themes studied under the 'lens' of Transformative Consumer Research (TCR), we have the vulnerability, which represents a state of impotence due to an imbalance in market interactions or the consumption of products and marketing messages. In this study, the focus is on the child consumer. With regard to the vulnerability of this market, this subject has not been widely studied and the field needs research. In this sense, the objective of this article is to identify the vulnerabilities of child consumers experienced in retail. For that, we carried out an exploratory research of a qualitative nature, in which the data collection took place through essays conducted with children aged eight to nine years, students of a school in the interior of the state of São Paulo. The data analysis was done through information categorization and content analysis. From data, it was possible to perceive that the vulnerability of the child in the retail is more associated with the presence of external factors, for example, absence of the desired products in the store, difficulty to find them, possibility of not identifying the product due to the Packaging with drawings, among others, than with the individual characteristics of children.
\end{abstract}

Keywords: Transformative consumer research. Vulnerability. Child consumer.

Esta obra está licenciada sob uma Licença Creative Commons Attribution 3.0.

\section{Introdução}

As crianças representam atualmente um mercado altamente lucrativo sendo constantemente alvo como qualquer outro mercado consumidor, das práticas de marketing, propagandas e táticas de vendas. São consideradas crianças, de acordo com o estatuto da criança e do adolescente, os indivíduos com até doze anos de idade incompletos.

No que diz respeito ao consumidor infantil, "no início, pensava-se apenas em um mercado a quem se poderia 
http://www.revista.ufpe.br/gestaoorg

vender balas e doces. Hoje, a visão de mercado ampliou-se para roupas, perfumes, jogos eletrônicos, cursos especiais, entre muitas outras oportunidades de negócio" (MENDES, 1998, p.2).

Os professionais de marketing têm desenvolvido forte interesse nas crianças como mercado consumidor, pois além das compras diretas, influenciam cada vez mais as decisões de consumo realizadas pelos adultos (ACUFF; REIHER, 1997; MCNEAL, 1992, 1998). O poder de compra desse grupo tem crescido por mais de três décadas em resposta ao aumento das fontes de rendas das crianças, diversas e complexas estruturas familiares e o contínuo crescimento das famílias com renda dupla (BAKIR; ROSE; SHAHAM, 2005).

No entanto, existe uma preocupação geral entre os pais, educadores, pesquisadores e o governo, sobre as consequências não intencionais ou negativas que a publicidade pode trazer para as crianças, como a adoção de uma mentalidade consumista ou o cultivo de hábitos alimentares pobres (BUIJZEN; VALKENBURG 2000; VERHELLEN et al., 2014).

É importante destacar que as crianças são confiantes e imaginativas, e os comerciais por meio de suas técnicas de venda podem incutir valores, crenças, determinar hábitos de compra e estabelecer um forte reconhecimento da marca. Para esse efeito, as informações fornecidas em comerciais são geralmente insuficientes e inadequadas na educação das crianças, uma vez que elas acreditam no que o anunciante está vendendo, não sendo capazes muitas vezes de identificar o que é ou não realidade (O'CASS; CLARLE, 2001). Estes autores destacam que os estudiosos devem explorar a questão da vulnerabilidade nas situações em que os pais não são capazes de filtrar os comerciais que atingem a criança.

Sendo assim, pode-se dizer que no contexto de consumo, a vulnerabilidade do consumidor infantil é largamente explorada e muitas vezes reforçada pelos profissionais de marketing. Para Andreasen e Manning (1990), os consumidores vulneráveis são aqueles que estão em desvantagem nas relações de troca devido a características que não são controláveis por eles mesmos no momento da transação. Os autores consideram vulneráveis: crianças, idosos, analfabetos, pobres, pessoas com deficiência, minorias étnicas e raciais.

No que diz respeito a vulnerabilidade do consumidor infantil, este tema não tem sido amplamente estudado e o campo carece de pesquisas sobre quem vivencia a vulnerabilidade e a percepção desse indivíduo sobre sua vulnerabilidade no contexto do consumo (BATAT, 2012). O referido autor sugere que a pesquisa transformativa do consumidor (TCR) deve explorar futuramente outros aspectos do comportamento da criança e do jovem, concentrando-se na percepção imprecisa que estes indivíduos possuem acerca da vulnerabilidade.

A TCR por sua vez, procura estudar os problemas que sejam significativos para os consumidores e gerar resultados que possam ser traduzidos em seu benefício (PETKUS, 2010). Tem por objetivos incentivar, orientar e divulgar pesquisas que primam pelo bem-estar e qualidade de vida dos consumidores, abordando temas como o materialismo, a pobreza, o consumo infantil e a influência que a publicidade pode exercer nas crianças, o alcoolismo, nutrição e obesidade, o consumo de drogas, pesquisas com grupos vulneráveis como os deficientes mentais, físicos e visuais, analfabetos, idosos, entre outros (ACR, 2013, PETKUS, 2010).

À luz do exposto, o presente artigo tem por objetivo identificar as vulnerabilidades do consumidor infantil vivenciadas no varejo. Tendo contextualizado o problema de pesquisa e definido o objetivo, apresenta-se em seguida os principais aspectos relacionados a pesquisa transformativa do consumidor, vulnerabilidade e o consumidor infantil. Posteriormente, a metodologia será abordada, seguida pela análise e discussão dos resultados, com uma articulação teórica dos achados, e finalmente, as considerações finais são apresentadas, incluindo as sugestões para futuras pesquisas.

\section{Revisão teórica}

\subsection{A pesquisa transformativa do consumidor}

A Association for Consumer Research (ACR) foi fundada em 1969 e desde então, tornou-se uma das maiores organizações internacionais de estudos direcionados ao comportamento do consumidor (MICK et al., 2012). Tem por missão, avançar em pesquisas nesta temática e facilitar o intercâmbio de informações científicas entre os membros da indústria, governo e academia em todo o mundo, e para isto, apoia uma série de conferências e estudos que abrangem várias áreas interessadas no comportamento do consumidor (ACR, 2013).

Em 1974, a ACR fundou o Journal of Consumer Research (JCR), que em seus anos iniciais, publicou artigos sobre crédito ao consumidor, nutrição, pobreza, consumidores idosos, entre outros. Nos anos de 1980 e 1990, o capitalismo despertou a atenção das pessoas e das empresas para os prazeres do consumo e aumento dos lucros, limitando assim, a preocupação com a qualidade de vida dos indivíduos. Nesse contexto, a ACR e o JCR pouco enfatizaram pesquisas que beneficiavam os consumidores e o meio ambiente. No entanto, o advento do século XXI, trouxe rupturas (como a crise econômica vivenciada nos Estados Unidos e os estudos da área de saúde que apontavam o consumo excessivo de alimentos não saudáveis e o crescimento do consumo de tabaco), que 
estimularam o renascimento de pesquisas sobre o bem-estar do consumidor e a ética do consumo (MICK et al., 2012).

Como resultado dessas e de outras tendências, debates sobre o capitalismo, materialismo, religião, consumo, imigração, discriminação, sustentabilidade ambiental e a miséria em muitas regiões do planeta mesmo diante de uma economia global dinâmica, intensificaram-se (MICK et al., 2012). Foi neste contexto, que David Mick canalizou estas preocupações e aspirações e lançou em 2005 o movimento denominado Transformative Consumer Research (TCR), ou ainda, Pesquisa Transformativa do Consumidor, que procura estudar os problemas que sejam significativos para os consumidores e gerar resultados que podem ser traduzidos em seu benefício (PETKUS, 2010; OZANNE et al., 2011). A palavra 'transformativa' significa uma importante e construtiva influência, incluindo o potencial para uma mudança edificante (MICK, 2006).

A TCR surgiu para unir pesquisadores que se dedicam a desenvolver estudos que buscam "respeitar, defender e melhorar a vida em relação às inumeráveis condições, demandas, potencialidades e efeitos do consumo" (MICK, 2006, p.2). Assim, a TCR além de contar com um significativo e crescente grupo de acadêmicos, parece estar prestes a alcançar nos próximos anos, um status dominante no campo do comportamento do consumidor.

Embora o interesse em questões relacionadas à TCR se mostre crescente, esta nova área não é considerada um mainstream da pesquisa acadêmica relacionada ao consumo, uma vez que a maioria dos pesquisadores continua a se concentrar na geração de conteúdos com relevância gerencial para organizações comerciais, enquanto que os pesquisadores da TCR procuram estudar os problemas que sejam significativos para os consumidores e gerem resultados que podem ser traduzidos para seu benefício (OZANNE et al., 2011).

Destaca-se que esta nova perspectiva lança o olhar sobre problemas reais a partir do ponto de vista dos públicos impactados e trabalha para melhorar a vida quotidiana e resolver problemas sociais (BAKER; MASON, 2012). Tem por objetivos incentivar, orientar e divulgar pesquisas que primam pelo bem-estar e qualidade de vida dos consumidores, abordando temas como o materialismo, a pobreza, o consumo infantil e a influência que a publicidade pode exercer nas crianças, o alcoolismo, nutrição e obesidade, o consumo de drogas, pesquisas com grupos vulneráveis como os deficientes mentais, físicos e visuais, analfabetos, idosos, entre outros (ACR, 2013, PETKUS, 2010).

Os desafios enfrentados pelos pesquisadores da pesquisa transformativa do consumidor são grandes, mas por outro lado, eles proporcionam uma oportunidade para realizar pesquisas que podem aliviar o sofrimento e melhorar o bem-estar dos consumidores, e nesse contexto, as recompensas superam os riscos (OZANNE et al., 2011).

Conforme o exposto percebe-se que a TCR possui como filosofia promover o bem-estar ao consumidor e se configura como uma iniciativa promissora que aspira mudanças na abordagem predominante de realização de pesquisas de consumo. Seus objetivos são desafiadores e exigem uma estratégia mais ampla para aumentar a probabilidade de sucesso (MARI, 2008).

\subsection{Vulnerabilidade do consumidor}

Levando em consideração o contexto do marketing, a ideia de vulnerabilidade do consumidor foi originalmente concebida com base em reações alérgicas a uma variedade de produtos. Somente nos últimos 20 anos tem-se uma definição ampliada que inclui outras condições ou situações (MORGAN; SCHULER; STOLTMAN, 1995).

Para Andreasen e Manning (1990), os consumidores vulneráveis são aqueles que estão em desvantagem nas relações de troca devido a características que não são controláveis por eles mesmos no momento da transação. Os autores consideram vulneráveis: crianças, idosos, analfabetos, pobres, pessoas com deficiência, minorias étnicas e raciais. Na visão de Smith e Cooper-Martin (1997), os consumidores vulneráveis são aqueles mais suscetíveis a prejuízos econômicos, físicos ou psicológicos devido a características que limitam suas habilidades de maximizar seu bem-estar e recursos.

No que se refere ao público infantil, foco do presente estudo, pode-se dizer que nos anos 70 a preocupação dos estudiosos de marketing com a influência da mídia e a comunicação persuasiva direcionada a um público considerado indefeso e vulnerável, foi baseada em políticas públicas que surgiram a partir das críticas de grupos ativistas e órgãos governamentais (ANDRADE, 2014; JOHN, 1999).

Há também o amparo do Código de Proteção e Defesa do Consumidor (1990), que apresenta parâmetros especiais para proteger a vulnerabilidade infantil nas relações de consumo e com a mídia. Segundo ele, o consumo infantil seria duplamente vulnerável, pois a noção de hipossuficiência é adotada para definir o consumidor (em relação ao produtor) e também a criança (em relação ao adulto). Por isso, como consumidora, a criança tem garantia de proteção diante da publicidade enganosa e 
A vulnerabilidade do consumidor infantil e jovem é considerada atualmente uma questão social importante a ser analisada em marketing e na área do comportamento do consumidor (BATAT, 2012). Os estudiosos também devem explorar a questão da vulnerabilidade no contexto em que os pais não são capazes de filtrar os comerciais que atingem a criança (O'CASS; CLARLE, 2001).

Batat (2012) conduziu um estudo sobre vulnerabilidade com indivíduos entre 11 e 15 anos, no qual por meio de uma imersão na subcultura jovem, teve por objetivo definir as dimensões relacionadas com a percepção que os jovens possuem acerca da vulnerabilidade. Os resultados revelaram seis categorias relacionadas à percepção da vulnerabilidade do consumidor jovem, sendo estas: impulsividade e autoconsciência; incapacidade de tomar decisões independentes e confiantes; incapacidade de resistir à pressão de grupos; falta de conhecimentos e experiência de consumo; paradoxo da sociedade digital e por fim utilização de comunidades online como fontes confiáveis de informação. Além disso, Batat (2012), identificou que os adolescentes podem vivenciar uma situação de vulnerabilidade com base em suas próprias experiências de consumo e também com base no que os outros veem em ambientes sociais e de consumo.

A definição de vulnerabilidade é por vezes, incompreendida ou mal equiparada com outros conceitos e aspectos como: características demográficas, discriminação, necessidades não satisfeitas, estigmatização, ou desvantagem (BAKER; GENTRY; RITTENBURG, 2005). Devido a esta falta de clareza, estes autores definem a vulnerabilidade como:

Um estado de impotência que surge a partir de um desequilíbrio nas interações de mercado ou do consumo de produtos e mensagens de marketing. Ocorre quando o controle não está na mão de um indivíduo, criando uma dependência de fatores externos (por exemplo, profissionais de marketing) para criar a equidade no mercado. A vulnerabilidade surge a partir da interação entre os estados individuais, as características individuais e as condições externas, dentro de um contexto no qual as metas de consumo podem não ser alcançadas e a experiência pode afetar a percepção que o indivíduo possui de si mesmo (BAKER; GENTRY; RITTENBURG, 2005, p. 134).

No entender de Brenkert (1998), os indivíduos vulneráveis, ao contrário dos que não são cingidos por esta condição, são caracterizados por possuírem experiências e capacidades que limitam suas habilidades para participar efetivamente das atividades relacionadas ao consumo. Baseado nestas características, o autor distinguiu quatro categorias de consumidores vulneráveis: (1) fisicamente vulneráveis, quando são excepcionalmente sensíveis aos produtos existentes no mercado, devido às condições físicas ou biológicas, por exemplo, alergias ou sensibilidade para determinados produtos ou substâncias comercializadas; (2) cognitivamente vulneráveis, quando os consumidores não possuem certos níveis de capacidade cognitiva para processar informações ou para perceber que determinada informação foi retida ou manipulados de forma enganosa, incluem-se aqui, crianças, idosos, e até mesmo aqueles com baixo nível de instrução; (3) motivacionalmente vulneráveis, quando não são capazes de resistir às tentações ordinárias e/ou engodos devido às suas próprias características individuais; (4) socialmente vulneráveis, quando a situação social os torna significativamente menos capazes do que outros para resistir a tentações, apelos, ou desafios que podem prejudicá-los.

Burden (1998) acredita que os consumidores podem ser vulneráveis por dois motivos. O primeiro deles refere-se à maior dificuldade que alguns podem apresentar em relação a outros na obtenção ou assimilação de informações necessárias para a tomada de decisões sobre a compra de bens e serviços. O segundo corresponde a uma maior perda de bem-estar como resultado da compra de produtos ou serviços inadequados, ou da não efetuação da compra quando seria do seu interesse fazê-la. Observa-se que o autor apresenta nessa informação dois fatores básicos para que uma situação de vulnerabilidade ocorra: "(1) presença de algumas características que são particulares de cada consumidor; e (2) presença de um agente externo que influencie ou crie essa situação" (SILVA, 2011, p. 39).

Observa-se que algumas definições de vulnerabilidade focam nas características ou limitações do indivíduo, enquanto outras se concentram nas condições externas e/ou em algum tipo de interação entre os fatores internos e externos (BAKER; GENTRY; RITTENBURG, 2005). Além disso, a vulnerabilidade do consumidor é um estado, não um status. Sendo de natureza multidimensional, ela ocorre em contextos específicos e não é necessariamente duradoura (KAUFMAN-SCARBOROUGH; CHILDERS, 2009). Conforme os autores, apesar da vulnerabilidade ser caracterizada pela dependência situacional e falta de controle no contexto do consumo, os indivíduos vulneráveis muitas vezes desenvolvem estratégias e mecanismos para lidar com esta situação. 
Por fim, é importante salientar o paradoxo existente no marketing, pois ao mesmo tempo em que contribui para que os consumidores vivenciem a vulnerabilidade no contexto do consumo, também pode oferecer meios para a redução desta situação (SHULTZ II; HOLBROOK, 2009). Conforme os autores, para reduzir a vulnerabilidade do consumidor, é necessário construir nas estruturas já existentes, caminhos que inspirem novas ideias, como também, políticas adequadas e práticas eficazes para a intervenção. Ou seja, tanto o Estado como os profissionais de marketing podem e devem criar soluções que promovam a segurança e o bem-estar dos consumidores que estão sujeitos a diversas vulnerabilidades no mercado.

\subsection{O consumidor infantil}

A pesquisa acadêmica referente ao comportamento do consumidor infantil remonta à década de 1950 com a publicação de alguns estudos isolados sobre temas como a fidelidade à marca e consumo conspícuo (JOHN, 1999). Conforme este autor, nos anos 60 houve um reconhecimento da criança como consumidora e um interesse em compreender a influência do marketing e dos pais nas decisões de compra. Sendo assim, apesar do número reduzido, estas pesquisas foram significativas no sentido de introduzir o tema à comunidade de marketing bem como apresentar métodos empíricos e informações sobre as crianças.

No entanto, apesar das crianças formarem um segmento fortemente atingido pelas ações do marketing, apenas em meados da década de 70 esta temática floresceu e ganhou visibilidade nas pesquisas de marketing (ANDRADE, 2014). Um novo impulso na área ocorreu com a publicação no Journal of Consumer Research do estudo intitulado 'Consumer Socialization', desenvolvido por Scott Ward em 1974. Conforme Ward (1974, p.2) a socialização do consumidor é definida "como processos pelos quais os jovens adquirem as habilidades, conhecimentos e atitudes relevantes para o seu funcionamento como consumidores".

Essa definição deu foco para uma nova geração de pesquisadores e um campo emergente de estudo, o qual possui uma gama de tópicos, como por exemplo, os conhecimentos que a criança possui em produtos, marcas, publicidade, compras, preços, estratégias de tomada de decisão, influência dos pais, abordagens de negociação, entre outros (JOHN, 1999). Tais aspectos refletem a crescente sofisticação das crianças como consumidoras, pois cada vez mais assumem um papel importante nas decisões de consumo familiar e na escolha dos produtos adquiridos (SOUZA; RÉVILLION, 2012).

Levando em consideração uma ampla revisão de 25 anos de pesquisa sobre a socialização do consumidor, é possível mencionar três fases deste processo: (1) fase perceptiva (3-7 anos de idade), durante a qual as crianças começam a distinguir os anúncios de programas, nomes de marcas associadas com categorias de produtos e alguns elementos do ponto de venda, ou seja, as crianças são capazes de entender o roteiro básico de consumo a partir de suas próprias observações; (2) fase analítica (7-11 anos), durante o qual as crianças capturam a intenção persuasiva da publicidade, começam a processar diferenças funcionais entre os produtos, e desenvolvem habilidades para discutir e negociar os itens desejados, bem como tomar decisões argumentadas; (3) fase reflexiva (11-16 anos), as crianças entendem as táticas e os apelos dos anúncios, tornam-se céticos em relação a eles, entendem roteiros de compras complexos, e tornam-se capazes de influenciar as compras (JOHN, 1999; VELOSO et al., 2008; WISENBIT; PRILUCK; PIROG, 2013.)

Os pais desempenham um papel importante na socialização das crianças (CARLSON; GROSSBART, 1988), que corresponde a um processo complexo e que envolve algumas dimensões, quais sejam: comunicação sobre o consumo, autonomia para consumir, influência e participação das crianças nas compras da família, e restrição ao consumo e exposição à mídia (CARLSON; GROSSBART 1988; ROSE, 1999). É importante destacar que outros fatores além da família estão associados a socialização da criança, como a mídia e amigos (SOLOMON, 2011).

Por fim, observa-se que outras razões importantes para o estudo da socialização do consumidor decorrem da necessidade de compreender o comportamento de consumo da família, mudanças e coerências no consumo entre as gerações, e o impacto das mudanças sociais no padrão de consumo dos jovens e da família.

\section{Procedimentos metodológicos}

Nesta seção são indicados os caminhos seguidos para o direcionamento e operacionalização da pesquisa. Tomando como referência o objetivo anteriormente apresentado, a opção foi por uma investigação exploratória de natureza qualitativa. Richardson (1999) afirma que uma pesquisa qualitativa pode ser caracterizada como uma tentativa de compreensão detalhada dos significados e características situacionais apresentadas pelos entrevistados. No entender de Flick (2004) a pesquisa qualitativa trata das construções da realidade - suas próprias construções e, especialmente, das construções presentes no campo ou nas pessoas que estuda.

Quanto aos fins, a pesquisa é classificada como exploratória, uma vez que há pouco conhecimento acumulado e sistematizado sobre a temática abordada. A carência de bibliografia e pesquisas anteriores, indicou a opção por uma pesquisa deste tipo, pois a intenção foi familiarizar-se com um assunto ainda pouco conhecido e explorado. 
http://www.revista.ufpe.br/gestaoorg

A pesquisa exploratória procura conhecer as características de um fenômeno para procurar explicações das causas e consequências do dito fenômeno (RICHARDSON, 1999). Na visão de Demo (2009), essa abordagem é utilizada em pesquisas nas quais busca-se entender fenômenos novos, explorar opiniões, atributos e atitudes.

Levando em consideração que a pesquisa qualitativa é criativa e interpretativa, esta fornece ao pesquisador uma diversidade de métodos para a coleta de materiais empíricos que variam da entrevista à observação direta, passando pela análise de artefatos, documentos e registros culturais e pelo uso de materiais visuais ou da experiência pessoal (DENZIN; LINCOLN, 2006). À luz do exposto, a coleta de dados ocorreu inspirada na técnica 'draw and write', 'desenhar e escrever', que como o próprio nome sugere, a criança desenhar uma imagem em resposta a um tema, assunto ou questão de pesquisa e logo após escrever todas as ideias associadas ao desenho (GIBSON et al., 2010). Esta técnica possui um lugar de destaque nas ferramentas exploratórias e fornece dados qualitativos ricos. Os pesquisadores atuais a consideram uma maneira potencialmente emocionante de envolver as crianças na pesquisa, além disso praticamente todas as crianças em idade escolar estão familiarizadas com a produção de desenhos e textos, portanto, isso pode ser considerado um método de coleta amigável e não ameaçador (BRADDING; HORSTMAN, 1999).

Um estudo que também foi fonte de inspiração quanto a metodologia empregada, foi o de O'Cass e Clarke (2001), que desenvolveram uma pesquisa sobre a preferência de marcas de produtos de Natal de crianças australianas. Os autores analisaram 422 cartas enviadas para o Papai Noel. A carta é uma modalidade redacional livre, que contém expressões de intenções, comportamentos e valores que expressam sentimentos acerca de um tema.

Para efeito deste estudo, a coleta de dados ocorreu, por meio de redações realizadas junto a crianças de uma escola estadual do interior de São Paulo, ao total foram coletadas 39 redações. As crianças cursam o $4^{\circ}$ ano do ensino fundamental, e possuem uma faixa etária entre oito e nove anos. Foi entregue pela professora folhas e lápis para cada criança, e solicitado que cada uma escrevesse uma redação relatando um episódio de compra ou as dificuldades encontradas ao comprarem um produto ou visitarem uma loja.

Por fim, no que diz respeito a análise dos dados, Gill (2009, p. 156) considera que "a análise tem como objetivo organizar e sumariar os dados de forma tal que possibilitem o fornecimento de respostas ao problema proposto para investigação". Para efeito deste estudo, a análise dos dados se deu por meio da categorização das informações e a análise de conteúdo. A categorização de informações consiste numa técnica para adequar as respostas dos elementos pesquisados, mediante o seu agrupamento em uma determinada quantidade de categorias (GILL, 2009). A análise de conteúdo pode ser utilizada para interpretar o conteúdo de documentos e textos de quaisquer naturezas, e conduz a descrições sistemáticas, quantitativas ou qualitativas, fundamentais para a interpretação e compreensão das mensagens e seus significados (MORAES, 1999). Para um maior entendimento do fenômeno estudado, a análise de conteúdo foi conduzida conforme as etapas sugeridas por Bardin (2000), sendo estas: 1) pré-análise, 2) exploração do material e 3) tratamento dos resultados, inferência e interpretação.

\section{Interpretação e discussão dos resultados}

De posse dos dados, buscou-se contextualizar o que foi proposto neste estudo. Inicialmente se faz importante caracterizar o perfil das crianças, as informantes da pesquisa. Sendo assim, foram coletadas 39 redações de estudantes do $4^{\circ}$ ano do ensino fundamental de uma escola estadual do interior de São Paulo, e destas, 17 crianças eram meninas e 21 meninos. A partir das redações foi possível perceber que ao relatarem episódios de compra, a maioria das crianças mencionaram a figura materna como principal acompanhante nessa atividade. Destaca-se que os pais, conforme apontam Carlson e Grossbart (1988), desempenham um papel importante na socialização das crianças.

Em relação aos produtos comprados, estes foram diversos, englobando roupas, sapatos, games, brinquedos, livros, presentes, entre outros, e quanto aos ambientes varejistas, foram mencionados shoppings centers, supermercados, e variadas lojas localizadas em centros comerciais.

Levando em consideração o objetivo deste estudo, que consiste em identificar as vulnerabilidades do consumidor infantil vivenciadas no varejo, e sabendo que os consumidores vulneráveis são aqueles que estão em desvantagem nas relações de troca devido a características que não são controláveis por eles mesmos no momento da transação (ANDREASEN; MANNING, 1990), apresenta-se a seguir alguns trechos das redações das crianças que evidenciam algumas situações vivenciadas que promovem ou reforçam sua vulnerabilidade:

"A vezes você quer um produto e fica difícil de encontrá-lo, pois pode existir vários deles e não ter o que você quer (...) um belo dia eu fui no shopping (...) vi algumas blusas lindas, e eu quis uma. Minha mãe procurou o meu número que é 10 ou 8, mas só tinha 6. A que tinha o meu número também era 
bonita, então acabei comprando, mas não foi a que eu tanto queria”. (Menina, informante 1).

"Eu queria comprar um presente do meu amigo (...) porque era aniversário dele o presente seria um carro de controle remoto. (...) eu não consegui encontrar em lugar nenhum, porque estava cheio de gente e quase não tinha mais brinquedos”. (Menino, informante 6).

"Quando vi uma linda camiseta, pedi para minha mãe, mas não coube em mim porque meu número era maior. Então triste da vida, minha mãe me mostrou uma camiseta e eu aceitei, mas queria a outra”. (Menino, informante 28).

Percebe-se que as informações presentes nos trechos acima, corroboram com as ideias de Smith e Cooper-Martin (1997), ao sugerirem que os consumidores vulneráveis são aqueles mais suscetíveis a prejuízos econômicos, físicos ou psicológicos devido a características que limitam suas habilidades de maximizar seu bem-estar e recursos. Nesse sentido, outras situações mencionadas pelas crianças evidenciam algum prejuízo econômico, físico ou psicológico como sugerido pelos autores supracitados, como pode ser observado a seguir:

"Eu não gosto quando chego em um lugar com uma certa quantia de dinheiro e o preço é mais caro. Uma vez fui a um lugar com minha tia, para comprar uma bola e tinha R\$15,00, mas vi que a bola custava R\$18,00, então não comprei a bola”. (Menino, informante 8).

"Certo dia, eu e minha mãe fomos até uma loja de brinquedos que fica bem longe da minha casa. Chegando lá, eu vi um brinquedo que eu queria muito, ele funcionava a pilhas. Voltei para a cada pus as pilhas no brinquedo e ele não funcionou. Voltamos a loja, e a gerente disse que era erro de fabricação(...)”. (Menina, informante 18).

"Um dia eu fui comprar uma sandália gladiadora (...) não deu nada certo porque tinha sandália na vitrine, mas não tinha no estoque mais meu número”. (Menina, informante 20).

"Eu fui vítima de uma cilada da loja. O moço deu um controle para mim olhar porque eu pedi, falou que tinha mais ou menos uns 10 controles, e logo depois falou que não tinha, que ia chegar logo, depois ele verificou no estoque e viu que não tinha mesmo". (Menino, informante 26).

Ao observar os trechos acima, é possível afirmar que algumas crianças apontaram como pontos ou situações negativas a ausência do produto que desejam na loja ou da numeração adequada por exemplo. Outros informantes mencionaram a questão dos elevados preços dos produtos em relação a quantia que possuíam no momento, e da contrariedade que vivenciam ao não efetivarem a compra. Sobre este último aspecto o informante 2, comenta o seguinte:

"Quando eu vou comprar alguma coisa, eu sempre vejo qual está mais barato e qual está mais caro, aquele que tiver mais caro na minha cabeça eu sempre coloco um ponto negativo”.

Conforme o Código de Proteção e Defesa do Consumidor (1990), o consumo infantil seria duplamente vulnerável, pois a noção de hipossuficiência é adotada para definir o consumidor (em relação ao produtor) e também a criança (em relação ao adulto) (PIEDRAS, 2013, p.152). Em relação ao produtor, algumas crianças relataram episódios que evidenciam a vulnerabilidade sendo promovida e reforçada por fatores externos.

"Quando eu vou em alguma loja, por exemplo [citou nome da loja], fico olhando preços e reparo muitas coisas caras, e eu também tenho dificuldade de achar as coisas nas prateleiras. Tem várias fileiras de produtos e quando quero alguma coisa não acho”. (Menina, informante 3).

"Em algumas lojas há tantas prateleiras e corredores que a minha familia demora para me achar. Em algumas lojas os produtos não estão organizados adequadamente para o consumidor encontrá-lo, eles ficam muito espalhados”. (Menina, informante 9).

"Quando a loja é muito grande e a pessoa está procurando o produto por exemplo, um shampoo, e não consegue encontrá-lo pois tem muitas coisas, e pode até se perder lá dentro (referindo-se à loja). (...) Quando o produto que a pessoa procura está no alto da prateleira, isso dificulta porque é difícil enxergar e de pegar, pois se a pessoa é baixa, ela terá que ficar pulando ou esticar o braço". (Menina, informante 10).

As afirmações realizadas pelas crianças descritas acima, revelam que a vulnerabilidade se referem a um estado de impotência que surge a partir de um desequilíbrio nas interações de mercado ou do consumo de produtos e mensagens de marketing. Ocorre quando o controle não está na mão de um indivíduo, criando uma dependência de fatores externos (por exemplo, profissionais de marketing) para criar a equidade no mercado (BAKER; GENTRY; RITTENBURG, 2005).

Por outro lado, observa-se que a vulnerabilidade surge a partir da interação entre os estados individuais, características individuais e condições externas, dentro de um contexto no qual as metas de consumo podem não 
http://www.revista.ufpe.br/gestaoorg

ser alcançadas e a experiência pode afetar a percepção que o indivíduo possui de si mesmo (BAKER; GENTRY; RITTENBURG, 2005, p. 134). Sobre as características individuais, é possível verificar este aspecto no relato do informante 7, ao afirmar o seguinte: “(...) e também alguma coisa que eu quero pegar no alto da prateleira, mas não consigo porque sou muito baixo".

Uma informante ressaltou que um dos fatores negativos na hora de comprar um produto são as embalagens, pois estas possuem cores chamativas e personagens de desenhos, o que dificulta a identificação e escolha do produto por exemplo. Além disso, a criança afirmou que as cores chamam a atenção e estimulam a vontade de experimentar o produto. Já outra informante aponta que: "Alguns produtos você procura nas lojas e você não acha pois está no fundo ou porque está faltando, e as lojas não repõem os produtos".

Conforme Kaufman-Scarborough e Childers (2009) no contexto do consumo, os indivíduos vulneráveis muitas vezes desenvolvem estratégias e mecanismos para lidar com esta situação. A partir desta afirmação, é possível verificar que o que foi relatado pelo informante 16 vão ao encontro das ideias propostas pelos referidos autores.

"Um dia eu fui em uma loja e comprei um perfume, mas a dificuldade para mim achar esse perfume foi grande. Eu procurei em todas as fileiras, e em todas as estantes, mas não encontrei. Então eu fui pedir ajuda para uma balconista, e ela me ajudou a encontrar o perfume e eu achei, só que era muito caro, e eu perguntei se tinha um perfume da mesma marca só que mais barato. E ela me mostrou os tipos que tinha e eu comprei". (Menino, informante 16).

Burden (1998) acredita que os consumidores podem ser vulneráveis por dois motivos. O primeiro deles refere-se à maior dificuldade que alguns podem apresentar em relação a outros na obtenção ou assimilação de informações necessárias para a tomada de decisões sobre a compra de bens e serviços. O segundo corresponde a uma maior perda de bem-estar como resultado da compra de produtos ou serviços inadequados, ou da não efetuação da compra quando seria do seu interesse fazê-la. Sobre este segundo aspecto, um informante menciona que quando busca um item com determinado desenho ou tema, e não encontra na loja, se sente decepcionado, e também se um outro consumidor comprar o produto que ele deseja, esperar o produto chegar e ter que voltar à loja são situações desagradáveis de vivenciar, ou seja, percebe-se que a criança se sentiu frustrada pela não efetivação da compra em decorrência de fatores externos.

A seguir são apresentadas as principais conclusões do estudo.

\section{Considerações finais}

A vulnerabilidade do consumidor infantil e jovem é considerada atualmente uma questão social importante a ser analisada em marketing e na área do comportamento do consumidor (BATAT, 2012). Esta temática não tem sido amplamente estudada e o campo carece de mais pesquisas. Sendo assim, o presente estudo teve por objetivo identificar as vulnerabilidades do consumidor infantil vivenciadas no varejo, por meio de uma pesquisa exploratória de natureza qualitativa.

Para Andreasen \& Manning (1990), vulneráveis são aqueles que estão em desvantagem nas relações de troca devido a características que não são controláveis por eles mesmos no momento da transação. Nesse sentido, a partir dos dados foi possível identificar situações que promoveram uma maior perda de bem-estar das crianças no momento da compra, como por exemplo: a ausência dos produtos desejados na loja, dificuldade de encontrálos e acessá-los em decorrência das altas prateleiras, possibilidade de não identificar o produto devido as embalagens com desenhos, e a grande variedade de produtos o que favorece a indecisão da criança no momento da escolha.

É importante mencionar que os adolescentes podem vivenciar uma situação de vulnerabilidade com base em suas próprias experiências de consumo, conforme Batat (2012), identificou em seu estudo. Além disso, com base nos dados e nas análises realizadas, observou-se que a vulnerabilidade da criança no varejo está mais associada com a presença de fatores externos mencionados anteriormente, do que com as características individuais das crianças. Quanto aos fatores individuais ou intrínsecos às crianças que proporcionaram situações vulneráveis no contexto de consumo, pode-se citar a baixa estatura, a qual dificultava o alcance de produtos nas prateleiras. No entanto, esse aspecto pode ser melhorado à medida que as lojas de varejo minimizem essas barreiras ao realocar os produtos de uma forma que seja de fácil acesso para todos os consumidores.

O presente estudo teve como limitação a ausência da pesquisadora na coleta de dados, o que impossibilitou o diálogo com as crianças no intuito de obter maiores informações sobre as experiências de consumo vivenciadas por elas. Porém acredita-se que tal limitação, não interferiu na qualidade dos resultados obtidos. Para estudos futuros sugere-se a realização de pesquisas com crianças de outras faixas etárias, investigações sobre a percepção que as crianças possuem acerca de suas vulnerabilidades, se os pais percebem e lidam com as vulnerabilidades dos seus filhos, e por fim mais pesquisas que abordem o tema vulnerabilidade, pois representa uma área com 
diversos aspectos a serem explorados.

Observa-se que este estudo em sua essência busca identificar as vulnerabilidades do consumidor infantil perante o mercado, no intuito de promover a melhoria das experiências de consumo vivenciadas pelas crianças, sendo assim, acredita-se que esta pesquisa se alinha a perspectiva da pesquisa transformativa do consumidor.

Por fim, é importante destacar que por ser exploratório, as discussões que este estudo enseja podem despertar o interesse de estudiosos da área do comportamento do consumidor em pesquisas situadas sob a 'lente' da TCR, principalmente sobre os aspectos da vulnerabilidade no contexto do mercado infantil.

\section{Referências}

ACR - ASSOCIATION FOR CONSUMER RESEARCH. Transformative Consumer Research. Disponível em < http://www.acrwebsite.org/web/tcr/transformative-consumer-research.aspx>. Acesso em: Mar. 2016.

ACUFF, D. S., REIHER, R. H. What kids buy and why: The psychology of marketing to kids. New York: The Free Press, 1997.

ANDRADE, M. A. Práticas de comunicação de marketing para crianças em websites. Revista Brasileira de Pesquisas de Marketing, Opinião e Mídia, v. 14, p. 19-37, 2014, 2011.

ANDREASEN, A. R.; MANNING, J. The dissatisfaction and complaining behavior of vulnerable consumers. Journal of Consumer Satisfaction, Dissatisfaction and Complaining Behavior, v. 3, p.12-20, 1990.

BAKER, S. M.; MASON, M. Toward a Process Theory of Consumer Vulnerability and Resilience: Illuminating Its Transformative Potential. In: MICK, David Glen; PETTIGREW, Simone; PECHMANN, Cornelia; OZANNE, Julie. Transformative consumer research: for personal and collective well-being. New York: Routledge, 2012.

BAKER, S. M.; GENTRY, J. W.; RITTENBURG, T. L. Building understanding of the domain of consumer vulnerability. Journal of Macromarketing 25:128-39, 2005.

BAKIR, A., ROSE, G. M.; SHOHAM, A. Consumption communication and parental control of children's television viewing: a multi-rater approach. Journal of Marketing Theory and Practice, 47-58, 2005.

BARDIN, L. Análise de conteúdo. 70. ed. Lisboa: Edições, 2000.

BATAT, W. How do Adolescents Define Consumer Vulnerability? Toward A Youth-Centric Approach. Advances in Consumer Researc $h, 40,2012$.

BRADDING, A.; HORSTMAN, M. Using the write and draw technique with children. European Journal of Oncology Nursing, 3(3), 170-175, 1999.

BRENKERT, G. G. Marketing and the Vulnerable. Business ethics quarterly, 7-20, 1998.

BUIJZEN, M.; VALKENBURG, P. M. The impact of television advertising on children's Christmas wishes. Journal of Broadcasting \& Electronic Media, v. 44, n. 3, p. 456-470, 2000.

BURDEN, R. Vulnerable consumer groups: quantification and analysis. Research Paper No. 15, prepared for the Office of Fair Trading, London: Office of Fair Trading, 1998.

CARLSON, L.; GROSSBART, S. Parental style and consumer socialization of children. Journal of consumer research, v. 15, n. 1, p. 77-94, 1988.

DEMO, P. (2009). Metodologia do conhecimento científico. São Paulo: Atlas, 2009.

DENZIN, N. K.; LINCOLN, Y. S. (2006). O planejamento da pesquisa qualitativa: teorias e abordagens. Porto Alegre: Artmed, 2006.

FLICK, U. Uma introdução à pesquisa qualitativa (Vol. 2). Porto Alegre: Bookman, 2004.

GIBSON, F.; ALDISS, S.; HORSTMAN, M.; KUMPUNEN, S.; RICHARDSON, A. Children and young people's experiences of cancer care: a qualitative research study using participatory methods. International journal of nursing studies, 47(11), 1397-1407, 2010.

GILL, R. Análise de discurso. In: BAUER, M. W.; GASKELL, G. Pesquisa qualitativa com texto, imagem e som. Petrópolis: Vozes, 2010.

JOHN, D. R. (1999). Consumer socialization of children: A retrospective look at twenty-five years of research. Journal of consumer research, 26(3), 183-213, 1999.

WISENBLIT, J. Z.; PRILUCK, R.; PIROG, S. F. The influence of parental styles on children's consumption. 
Journal of Consumer Marketing, v. 30, n. 4, p. 320-327, 2013.

KAUFMAN-SCARBOROUGH. C.; CHILDERS, T. Understanding markets as online public places: insights from consumers with visual impairments. Journal of Public Policy \& Marketing. V. 28, n.1, p. 16-28, 2009.

MARI, C.; Doctoral education and transformative consumer research. Journal of Marketing Education. Jan., 2008.

MCNEAL, J. U. Children as customers. Lexington, KY: Lexington Books, 1992.

MCNEAL, J. U. Tapping the three kids' markets. American Demographics, April, 36-41, 1998.

MENDES, Manoel Everardo P. A criança brasileira como um fenômeno de consumo: Perspectivas no mercado de iogurtes a partir da análise de grupos motivacionais. XXII EnANPAD, 1998.

MICK, D. G. Meaning and mattering through transformative consumer research. Advances in Consumer Research, Washington, v. 33, n. 1, pp. 1-4, 2006.

MICK, D. G.; PETTIGREW, S.; PECHMANN, C.; OZANNE, J. Transformative consumer research: for personal and collective well-being. New York: Routledge, 2012.

MORAES, R. Análise de conteúdo. Revista Educação, Porto Alegre, v. 22, n. 37, pp. 7-32, 1999.

MORGAN, F. W.; SCHUlER, D. K.; STOLTMAN, J. J. A framework for examining the legal status of vulnerable consumers. Journal of Public Policy \& Marketing, p. 267-277, 1995.

O'CASS, A.; CLARKE, P. Dear Santa, do you have my brand? A study of the brand requests, awareness and request styles at Christmas time. Journal of Consumer Behaviour, v. 2, n. 1, p. 37-53, 2002.

OZANNE, J; PETTIGREW, S; CROCKETT, D; FUAT FIRAT, A.; DOWNEY, H; PESCUD, M. The Practice of transformative consumer research--some issues and suggestions. Journal of Research for Consumers 19, 2011.

PETKUS, E. Incorporating transformative consumer research into the consumer behavior course experience. Journal of Marketing Education, 32 (3), 292-299. 2010.

PIEDRAS, E. R. (2013). Vulnerabilidade ou resistência? Um panorama da questão do consumo infantil de alimentos permeado pelo marketing e a mídia. Comunicação, Mídia e Consumo, 10(29), 2013.

RICHARDSON, R. J. Pesquisa social: métodos e técnicas. 3. ed. São Paulo: Atlas, 1999.

ROSE, G. M. Consumer socialization, parental style, and developmental timetables in the United States and Japan. The Journal of Marketing, 105-119, 1999.

SHULTZ II, C. J.; HOLBROOK, M. B. The paradoxical relationships between marketing and vulnerability. Journal of Public Plicy \& Marketing, v. 28, n.1, p. 124-127. 2009.

SILVA, A. P. SER OU NÃO SER? EIS A QUESTÃO: uma investigação sobre a vulnerabilidade dos consumidores (Doctoral dissertation, Dissertação (Mestrado em administração). Universidade Federal da Paraíba, João Pessoa, 2011.

SMITH, N. C.; COOPER-MARTIN, E. Ethics and target marketing: the role of product harm and consumer vulnerability. Ethics and Target Marketing 61 (July): 1-20, 1997.

SOLOMON, Michael R. O comportamento do consumidor: comprando, possuindo e sendo. 7. ed. Porto Alegre: Bookman, 2011.

SOUZA, Â. R. L.; RÉVILLION, J. P. P. Novas estratégias de posicionamento na fidelização do consumidor infantil de alimentos processados. Ciência Rural, 42(3), 573-580, 2012. VELOSO, A. R., HILDEBRAND, D. F. N., DARÉ, P. R. C.; CAMPOMAR, M. C. A criança no varejo de baixa renda. RAE eletrônica, 7(2), 2008.

VERHELLEN, Y.; OATES, C.; PELSMACKER, P.; DENS, N. Children's Responses to Traditional Versus Hybrid Advertising Formats: The Moderating Role of Persuasion Knowledge. Journal of Consumer Policy, 37(2), 235-255, 2014. 